\title{
Brief Report: Inhibitory Control of Socially Relevant Stimuli in Children with High Functioning Autism
}

\author{
Hilde M. Geurts · Sander Begeer · Lex Stockmann
}

Published online: 19 June 2009

(C) The Author(s) 2009. This article is published with open access at Springerlink.com

\begin{abstract}
The current study explored whether inhibitory control deficits in high functioning autism (HFA) emerged when socially relevant stimuli were used and whether arousal level affected the performance. A Go/NoGo paradigm, with socially relevant stimuli and varying presentation rates, was applied in 18 children with HFA (including children with autism or Asperger syndrome) and 22 typically developing children (aged 8-13 years). Children with HFA did not show inhibitory control deficits compared to the control group, but their performance deteriorated in the slow presentation rate condition. Findings were unrelated to children's abilities to recognize emotions. Hence, rather than a core deficit in inhibitory control, low arousal level in response to social stimuli might influence the responses given by children with HFA.
\end{abstract}

Keywords Autism - Arousal Emotion · Inhibitory control $\cdot$ Executive functions

H. M. Geurts $(\bowtie)$

Department of Psychonomics, University of Amsterdam, Roetersstraat 15, 1018 WB Amsterdam, The Netherlands e-mail: h.m.geurts@uva.nl

\section{S. Begeer}

Department of Developmental Psychology, VU University, Amsterdam, The Netherlands

L. Stockmann

Center for Autism, Oestgeest, The Netherlands

Present Address:

H. M. Geurts

Dr. Leo Kannerhuis, Doorwerth, The Netherlands

\section{Introduction}

One of the most influential cognitive theories of autism spectrum disorders (ASD) highlights the primary role of deficits in executive functions (Geurts et al. 2009; Hill 2004; Pennington and Ozonoff 1996; Russell 1997), the cognitive control processes that guide the ability to monitor ongoing performance in a dynamically changing environment. Within social interactions it is necessary to select and initiate complex behaviors in response to the specific necessities of the social environment (Bachevalier and Loveland 2006). Hence, the ability to generate appropriate responses during social interactions involves selecting the most fitting response while inhibiting those responses deemed inappropriate which is an important aspect of executive functioning. Despite its suggested relevance to social functioning, executive functions are mainly studied in non-social domains (Hill 2004), using tasks that focus on specific, elementary abilities such as planning behaviour and inhibitory control (Sergeant et al. 2002). Findings on inhibitory control in ASD are particularly mixed, with multiple reports on both deficits (e.g., Christ et al. 2007; Geurts et al. 2004, 2008; Solomon et al. 2008), and attainments (e.g., Christ et al. 2007; Happé et al. 2006; Kana et al. 2007; Ozonoff and Jensen 1999; Raymaekers et al. 2007; Schmitz et al. 2006), which may in part be due to differences in arousal modulation (Liss et al. 2006; Raymaekers et al. 2004). The current study will focus on the role of arousal modulation in the inhibitory control of socially relevant stimuli of children with ASD.

Over-arousal, attained by fast presentation rates of stimuli, can cause inhibitory control deficits in participants with ASD (Raymaekers et al. 2004; Sanders 1998). However, when non-social stimuli are used, these deficits are not always found in children with ASD, even when fast 
presentation rates were used (e.g., Christ et al. 2007; Happé et al. 2006; Kana et al. 2007; Raymaekers et al. 2007; Schmitz et al. 2006). The role of arousal modulation in inhibitory control tasks may be more clear when social stimuli are used, e.g., emotional faces, which are known to elicit both hypo- and hyper-responsiveness in children with ASD, likely due to impaired arousal modulation (Baker et al. 2008; Bolte et al. 2008; Corden et al. 2008a, b; Rogers and Ozonoff 2005; Schoen et al. 2008).

In the current study, we investigated inhibitory control deficits in children with ASD when processing socially relevant stimuli. Children with high functioning autism (HFA, including children with autism and with Asperger syndrome) were compared to typically developing control children on two experimental tasks: (a) a Go/NoGo-task with emotional stimuli presented at two different presentation rates; and (b) an emotion recognition task to determine whether children with HFA have deficits in the recognition of simple emotions. We hypothesized a limited ability to inhibit responses to social stimuli in children with ASD compared to controls. Furthermore, we explored the effect of the presentation rate (i.e., arousal level) on the ability to inhibit the prepotent motor response to these socially relevant stimuli.

\section{Methods}

\section{Participants}

Twenty-two children with HFA and 22 typically developing control children participated in this study. Participants with HFA fulfilled established diagnostic criteria according to the DSM-IV-TR (American Psychiatric Association 2000), as well as the autism algorithm cut-offs on two questionnaires that assess the defining social problems of children with HFA: Children's Communication Checklist (CCC, Bishop 1998) and the Children's Social Behavior Questionnaire (CSBQ, Luteijn et al. 2002). Three children were excluded from the study because they had an estimated IQ below 75 as measured by the short version of the Dutch Wechsler Intelligence Scale for Children (WISC-III; de Kort et al. 2002). One child refused to do all the tests. Therefore, eventually 18 children with a clinical diagnosis of autism $(n=7)$ or Asperger Syndrome $(n=11)$ aged 8-13 years participated in this study. One participant with HFA was on methylphenidate, but discontinued medication at least $20 \mathrm{~h}$ before testing allowing for a complete washout. None of the other children used any kind of medication.

All children had an estimated IQ above 75 (range HFA: 82-144; range controls: 75-154). The two groups did not differ from each other with respect to age, $F(1,40)<1, n$ s,
Table 1 Controls and HFA: group means and standard deviations for age, IQ, and, rating scales

\begin{tabular}{|c|c|c|c|c|c|}
\hline \multirow[t]{2}{*}{ Measure } & \multicolumn{5}{|c|}{ Group } \\
\hline & \multicolumn{2}{|c|}{ Controls $(n=22)$} & \multicolumn{3}{|c|}{$\operatorname{HFA}(n=18)$} \\
\hline \multirow[t]{2}{*}{ Gender (Boys/Girls) } & \multicolumn{2}{|c|}{$19 / 3$} & \multicolumn{2}{|c|}{$16 / 2$} & \multirow[b]{2}{*}{$\begin{array}{l}\text { Group } \\
\text { comparison } \\
(p)\end{array}$} \\
\hline & $M$ & SD & $M$ & SD & \\
\hline Age & 10.3 & 1.4 & 10.3 & 1.6 & .96 \\
\hline FSIQ & 103.2 & 24.1 & 108.0 & 19.0 & .50 \\
\hline \multicolumn{6}{|l|}{$C C C$} \\
\hline Speech Output & 34.0 & 2.7 & 33.9 & 3.1 & .91 \\
\hline Syntax & 31.5 & 0.9 & 31.6 & 0.7 & .74 \\
\hline Inappropriate Initiation & 28.2 & 1.8 & 24.1 & 3.0 & $<.001$ \\
\hline Coherence & 34.8 & 1.8 & 30.0 & 3.2 & $<.001$ \\
\hline Stereotyped Conversation & 28.5 & 1.8 & 21.6 & 3.8 & $<.001$ \\
\hline $\begin{array}{l}\text { Use of Conversational } \\
\text { Context }\end{array}$ & 30.4 & 1.4 & 23.8 & 2.8 & $<.001$ \\
\hline Conversational Rapport & 32.3 & 2.0 & 26.5 & 2.9 & $<.001$ \\
\hline Social Relationships & 33.0 & 1.2 & 27.4 & 2.6 & $<.001$ \\
\hline Interests & 31.2 & 1.7 & 26.2 & 3.0 & $<.001$ \\
\hline \multicolumn{6}{|l|}{$C S B Q$} \\
\hline Not optimally tuned & 3.7 & 3.6 & 12.2 & 4.5 & $<.001$ \\
\hline Reduced social contacts & 1.6 & 3.0 & 9.6 & 3.6 & $<.001$ \\
\hline Orientation problems & 1.2 & 1.9 & 6.9 & 3.5 & $<.001$ \\
\hline Problems in understanding & 1.5 & 1.4 & 8.7 & 3.5 & $<.001$ \\
\hline Stereotype behavior & 0.6 & 1.1 & 4.6 & 3.1 & $<.001$ \\
\hline Resistance to change & 0.2 & 0.5 & 3.2 & 3.1 & $<.001$ \\
\hline Total score & 9.0 & 8.2 & 45.3 & 11.2 & $<.001$ \\
\hline
\end{tabular}

Note. CCC, children's communication checklist, $C S B Q$, Children's Social Behavior Questionnaire, FSIQ, full scale IQ, $H F A$, high functioning autism (including children with a diagnosis of autism and Asperger syndrome, see text)

Note that the lower the score on the CCC, the more impaired the child is, while in the CSBQ a higher score indicates impairment

$\eta^{2}=.00$, FSIQ, $F(1,40)<1, n \mathrm{~s}, \eta^{2}=.01$, and gender, $\chi^{2}$ $(1, N=40)=.058, n \mathrm{~s}$. As expected, the parents of the children with HFA reported more problems when compared to typically developing children on all scales of the CCC and the CSBQ (see Table 1). The parents of the control children indicated that none of these children, or their siblings, was known with behavioural problems or a psychiatric or neurological diagnosis.

\section{Material}

Emotional inhibition task. In line with Raymaekers et al. $(2004 ; 2007)$ the inhibition task was a Go/NoGo paradigm with two types of trials: Go-trials and NoGo-trials. In the middle of the computer screen there was a small square as 
constant fixation point. On each trial a visual stimulus, either a face with a happy expression (Go-trial) or a face with an angry expression (NoGo-trial) appeared for $300 \mathrm{~ms}$. In a Go-trial, the participants were instructed to press a response key with their index finger of their dominant hand if a face with a happy expression appeared, whereas in a NoGo-trial, participants had to refrain from responding if a face with an angry expression appeared. To enhance the ecological validity of the emotional stimuli we chose emotions that promote approaching behavior in the Go-trial (happy expressions), and emotions that promote aversive behavior in the NoGo-trial (angry expressions, Frijda 1986; Isen 1987). Eight different faces were used as stimuli, taken from the Karolinska Directed Emotional Faces set which consists of 4,900 pictures of human facial expressions (Lundqvist et al. 1998). The set contains 70 actors (35 male, 35 female; age range 20-30 years) each displaying seven different emotional expressions. In our selection there were equal numbers of men and women, all wearing the same plain blue-grey t-shirt and each person was shot once looking happy and once looking angry.

There were two conditions within this task, a fast presentation rate (determined in a pilot study and following Raymaekers et al. 2007), using a $2 \mathrm{~s}$ interstimulus interval (defined in terms of onset to offset) and a slow presentation rate, using a $6 \mathrm{~s}$ interstimulus interval. To keep the time on task effect equal for both conditions, the fast condition consisted of 200 trials (160 Go-trials and 40 NoGo-trials) and the slow condition consisted of 80 trials (64 Go-trials and 16 NoGo-trials). So in each condition $20 \%$ of the trials were NoGo-trials. The participants started with 20 practice trials. In these practice trials other faces were used than in the experimental trials. The duration for each condition, including instructions and practicing, was $\sim 10 \mathrm{~min}$. Hence, without instructions the condition with the $2 \mathrm{~s}$ interstimulus interval lasted $7.6 \mathrm{~min}$, while the $6 \mathrm{~s}$ condition lasted $8.4 \mathrm{~min}$.

The individual mean reaction times of correct Go-trials were calculated. Second, the intrasubject variability (standard deviation of the mean reaction time of correct Gotrials) was calculated as this is also linked to arousal modulation (Raymaekers et al. 2004, 2007). Third, the percentage of errors was calculated for each individual. The percentage of errors is the number of commission errors (the participant responded to a NoGo-trial) divided by the total number of NoGo-trials. Typically, deficient inhibitory control leads to an increased error rate on NoGotrials (Casey et al. 1997).

Emotion recognition task. In this task the participants had to decide whether the person on the picture displayed a happy or an angry emotion by pushing one of two buttons, namely a blue one for happy and a red one for angry. Stimuli from the Karolinska Directed Emotional Faces set
(Lundqvist et al. 1998) were used, which were similar to the type of stimuli used in the emotional inhibition task. The task consisted of 80 trials of 16 different faces, half of which displaying a happy emotion, the other half displaying an angry emotion.

\section{Procedure}

After the parents filled out both questionnaires and written informed consents were obtained, the participants were tested. Within the inhibition task the order of two presentation rates were counterbalanced across the participants. The emotional decision task was always administrated last to prevent cross-over effects. All participants received a small gift at the end of the test session and the parents or caregivers were sent reports of the overall findings of the study.

\section{Results}

Mean reaction time and intrasubject variability (arousal). All children were faster and less variable in the fast presentation rate compared to the slow condition, respectively $F(1,38)=74.07, p<.001, \eta^{2}=.66$ and $F(1,38)=$ $10.00, p<.005, \eta^{2}=.21$. In their overall performance children with HFA could not be differentiated from control children on response speed, $F(1,38)=2.59, n \mathrm{~s}, \eta^{2}=.06$, however, the responses of the children with HFA were more variable than the control children, $F(1,38)=4.09$, $p<.05, \eta^{2}=.10$. A Group * Presentation rate interaction, $F(1,38)=7.00, p<.02, \eta^{2}=.16$ (see Table 2), indicated a different effect of presentation rate on response speed in HFA and controls. While the fast presentation rate elicited similar mean reaction times in both groups $(n \mathrm{~s})$, the slow presentation rate elicited slower responses in the HFA

Table 2 Group means and standard deviations for the emotional inhibition task for controls and participants with HFA

\begin{tabular}{|c|c|c|c|c|c|c|c|c|}
\hline \multirow[t]{4}{*}{ Measure } & \multicolumn{8}{|l|}{ Group } \\
\hline & \multicolumn{4}{|c|}{ Controls } & \multicolumn{4}{|l|}{ HFA } \\
\hline & \multicolumn{2}{|c|}{$\begin{array}{l}\text { Fast } \\
(2 \mathrm{~s} \text { ISI })\end{array}$} & \multicolumn{2}{|c|}{$\begin{array}{l}\text { Slow } \\
\text { (6 s ISI) }\end{array}$} & \multicolumn{2}{|c|}{$\begin{array}{l}\text { Fast } \\
(2 \mathrm{~s} \text { ISI) }\end{array}$} & \multicolumn{2}{|c|}{$\begin{array}{l}\text { Slow } \\
\text { (6 s ISI) }\end{array}$} \\
\hline & $M$ & SD & $M$ & SD & $M$ & SD & $M$ & SD \\
\hline MRT & 446.6 & 80.3 & 510.6 & 87.6 & 476.2 & 129.4 & 597.0 & 168.3 \\
\hline SD MRT & 125.7 & 42.33 & 134.2 & 45.2 & 151.2 & 63.0 & 183.1 & 90.0 \\
\hline$\%$ Errors & 10.3 & 6.0 & 10.2 & 5.4 & 12.7 & 5.1 & 11.3 & 5.0 \\
\hline
\end{tabular}

Note. HFA, high functioning autism (including children with a diagnosis of autism and Asperger syndrome, see text), ISI, inter stimulus interval, $M R T$, mean reaction time, $S D$, standard deviation 
than in the control group, $p<.05$. There was no differential effect of presentation rate on intrasubject variability for the two groups, $F(1,38)=3.36, n \mathrm{~s}, \eta^{2}=.08$.

Percentage errors (inhibitory control): All children made less errors when the presentation rate was slow than when the presentation rate was fast, $F(1,38)=6.96, p<.02$, $\eta^{2}=.16$, but no Group, $F<1, n \mathrm{~s}, \eta^{2}=.01$, nor interaction effects, $F(1,38)=1.08, n \mathrm{~s}, \eta^{2}=.03$, were found.

There were no group differences in the recognition of happy or angry faces on the emotion recognition task (Response speed: Group, $F(1,38)=2.88, n \mathrm{~s}, \eta^{2}=.07$; Group * Emotion, $F(1,38)=2.52, n \mathrm{~s}, \eta^{2}=.06$ : Accuracy: Group, $F(1,38)=1.18, n \mathrm{~s}, \eta^{2}=.03$, Group $*$ Emotion, $F<1, n \mathrm{~s}, \eta^{2}=.02$.).

\section{Discussion}

The current results suggest that children with HFA are able to exert adequate inhibitory control when processing facial expressions, which is in line with most former studies that used neutral stimuli (e.g., Christ et al. 2007; Happé et al. 2006; Kana et al. 2007; Raymaekers et al. 2007; Schmitz et al. 2006). Despite their equal accuracy, children with HFA responded disproportionably slower than controls in the slow, but not in the fast presentation rate condition. This slowness is generally not related to inhibitory control deficits per se (Casey et al. 1997), and could not be attributed to the inability to recognize simple emotions. In line with Raymaekers et al. (2004) we found that presentation rate affected children with HFA differently than typically developing children, however, our pattern of findings differs from the earlier reported pattern. Raymaekers et al. (2004) showed that on a neutral inhibitory control task adults with ASD were more impaired (as reflected by accuracy measures) when the presentation rate was fast, while we found that children with HFA were more impaired when the presentation rate was slow (as reflected by response speed measures). Among others, the two studies differed in the timing of the fast presentation rates and in the age of the participants. In a study in children with HFA, with a similar fast presentation rate as in the current study, Raymaekers et al. (2007) could not replicate the former adult pattern of findings (Raymaekers et al. 2004). This suggests that the effect of presentation rate is both age and stimulus dependent, as in children the presentation rate only seems to influence performance when emotional stimuli are used.

The current findings, including the enhanced response time variability, suggest a lack of efficient arousal modulation, motivation, or reduced attention (e.g., Garretson et al. 1990) in children with HFA. When stimuli are presented at a slow pace it might be harder to sustain attention or to keep a sufficient amount of motivation. We tried to eliminate sustained attention as a confounding factor to keep the time on task exactly the same in both presentation rate conditions and by counterbalancing this presentation rate (see also Christ et al. 2007). However, it is still possible that the children with HFA were less motivated and put in less effort when the presentation rate was slow. Whether this is especially the case when socially relevant stimuli are used needs to be studied in future research. Although one might interpret these findings as evidence for under-arousal in children with HFA when confronted with facial expressions, we believe that replication studies (in which psycho physiological measures, such as heart rate variability or skin conductance, of arousal are included; see also Geurts et al. 2009) are needed before such a conclusion can be drawn.

A potential confound of the experimental set up might be the choice to include emotions with response tendencies in line with the requested action in the emotional inhibition task. However, reversing the instruction by requesting responses to angry expressions and no responses to happy expressions could introduce an additional inhibition element to the task, above the inhibitory control that is inherent to the Go/NoGo-task. Moreover, this is not likely to explain the current findings.

In sum, we show that even when more socially relevant stimuli are used children with HFA do not show inhibitory control deficits. However, motivation and/or arousal might be a factor that influences the processing of socially relevant stimuli as slow presentation rates resulted in more profound performance decrements in children with HFA as compared to typically developing children. How and when motivation plays a role in children with HFA needs to be addressed in future research as this might give us insight in how we can motivate children with HFA in such a way that in daily life their performances increase.

Acknowledgments We want to thank all the parents and children that participated in the current study and Channa Hijmans and Mireille Visser-Klaver for testing the participating children. We want to thank Mark Rotteveel for introducing us to the Karolinska Directed Emotional Faces set.

Open Access This article is distributed under the terms of the Creative Commons Attribution Noncommercial License which permits any noncommercial use, distribution, and reproduction in any medium, provided the original author(s) and source are credited.

\section{References}

American Psychiatric Association. (2000). Diagnostic and statistical manual of mental disorders (4th ed.). Washington DC: Author.

Bachevalier, J., \& Loveland, K. A. (2006). The orbitofrontalamygdala circuit and self-regulation of social-emotional 
behavior in autism. Neuroscience and Biobehavioral Reviews, 30, 97-117. doi:10.1016/j.neubiorev.2005.07.002.

Baker, A. E. Z., Lane, A., Angley, M. T., \& Young, R. L. (2008). The relationship between sensory processing patterns and behavioural responsiveness in autistic disorder: A pilot study. Journal of Autism and Developmental Disorders, 38, 867-875. doi: 10.1007/s10803-007-0459-0.

Bishop, D. V. M. (1998). Development of the children's communication checklist (CCC): A method for assessing qualitative aspects of communicative impairment in children. Journal of Child Psychology and Psychiatry and Allied Disciplines, 39, 879-891. doi:10.1017/S0021963098002832.

Bolte, S., Feineis-Matthews, S., \& Poustka, F. (2008). Brief report: Emotional processing in high-functioning autism-physiological reactivity and affective report. Journal of Autism and Developmental Disorders, 38, 776-781. doi:10.1007/s10803-007-0443-8.

Casey, B. J., Castellanos, F. X., Giedd, J. N., Marsh, W. L., Hamburger, S. D., Schubert, A. B., et al. (1997). Implication of right frontostriatal circuitry in response inhibition and attentiondeficit/hyperactivity disorder. Journal of the American Academy of Child and Adolescent Psychiatry, 36, 374-383. doi:10.1097/ 00004583-199703000-00016.

Christ, S. E., Holt, D. D., White, D. A., \& Green, L. (2007). Inhibitory control in children with autism spectrum disorder. Journal of Autism and Developmental Disorders, 37, 1155-1165. doi: 10.1007/s10803-006-0259-y.

Corden, B., Chilvers, R., \& Skuse, D. (2008a). Avoidance of emotionally arousing stimuli predicts social-perceptual impairment in Asperger's syndrome. Neuropsychologia, 46, 137-147. doi:10.1016/j.neuropsychologia.2007.08.005.

Corden, B., Chilvers, R., \& Skuse, D. (2008b). Emotional modulation of perception in Asperger's syndrome. Journal of Autism and Developmental Disorders, 38, 1072-1080. doi:10.1007/s10803007-0485-y.

de Kort, W., Compaan, E. L., Bleichrodt, N., Resing, W. C. M., Schittekatte, M., Bosmans, M., et al. (2002). WISC-III NL. Handleiding. London: The Psychological Corporation.

Frijda, N. H. (1986). The emotions. Cambridge: Cambridge University Press.

Garretson, H. B., Fein, D., \& Waterhouse, L. (1990). Sustained attention in children with autism. Journal of Autism and Developmental Disorders, 20, 101-114. doi:10.1007/BF0220 6860.

Geurts, H. M., Corbett, B., \& Solomon, M. (2009). The paradox of cognitive flexibility in autism. Trends in Cognitive Sciences, 13, 74-82. doi:10.1016/j.tics.2008.11.006.

Geurts, H. M., van Meel, K., \& Luman, M. (2008). What's in a game: The effect of social motivation on interference control in boys with ADHD and autism spectrum disorders. Journal of Child Psychology and Psychiatry and Allied Disciplines, 49, 848-857. doi:10.1111/j.1469-7610.2008.01916.x.

Geurts, H. M., Verté, S., Oosterlaan, J., Roeyers, H., \& Sergeant, J. A. (2004). How specific are executive functioning deficits in Attention Deficit Hyperactivity Disorder and autism? Journal of Child Psychology and Psychiatry and Allied Disciplines, 45, 836-854. doi:10.1111/j.1469-7610.2004.00276.x.

Happé, F., Booth, R., Charlton, R., \& Hughes, C. (2006). Executive function deficits in autism spectrum disorders and attentiondeficit/hyperactivity disorder: Examining profiles across domains and ages. Brain and Cognition, 61, 25-39. doi:10.1016/ j.bandc.2006.03.004.

Hill, E. L. (2004). Evaluating the theory of executive dysfunction in autism. Developmental Review, 24, 189-233. doi:10.1016/ j.dr.2004.01.001.
Isen, A. M. (1987). Positive affect, cognitive-processes, and socialbehavior. Advances in Experimental Social Psychology, 20, 203-253. doi:10.1016/S0065-2601(08)60415-3.

Kana, R. K., Keller, T. A., Minshew, N. J., \& Just, M. A. (2007). Inhibitory control in high-functioning autism: Decreased activation and underconnectivity in inhibition networks. Biological Psychiatry, 62, 198-206. doi:10.1016/j.biopsych.2006.08.004.

Liss, M., Saulnier, C., Kinsbourne, D. F., \& Kinsbourne, M. (2006). Sensory and attention abnormalities in autistic spectrum disorders. Autism, 10, 155-172. doi:10.1177/1362361306062021.

Lundqvist, D., Flykt, A., \& Öhman, A. (1998). Karolinska directed emotional faces set $(K D E F)$. Sweden: Department of Neurosciences, Karolinska Hospital Stockholm.

Luteijn, E. F., Minderaa, R., \& Jackson, S. (2002). Vragenlijst voor Inventarisatie van Sociaal gedrag bij Kinderen (VISK, CBSK in English), handleiding. Lisse: Swets testpublishers.

Ozonoff, S., \& Jensen, J. (1999). Brief report: Specific executive function profiles in three neurodevelopmental disorders. Journal of Autism and Developmental Disorders, 29, 171-177. doi: 10.1023/A:1023052913110.

Pennington, B. F., \& Ozonoff, S. (1996). Executive functions and developmental psychopathology. Journal of Child Psychology and Psychiatry and Allied Disciplines, 37, 51-87. doi:10.1111/ j.1469-7610.1996.tb01380.x.

Raymaekers, R., Antrop, I., van der Meere, J. J., Wiersema, J. R., \& Roeyers, H. (2007). HFA and ADHD: A direct comparison on state regulation and response inhibition. Journal of Clinical and Experimental Neuropsychology, 29, 418-427. doi:10.1080/1380 3390600737990.

Raymaekers, R., van der Meere, J., \& Roeyers, H. (2004). Event-rate manipulation and its effect on arousal modulation and response inhibition in adults with high functioning autism. Journal of Clinical and Experimental Neuropsychology, 26, 74-82. doi: 10.1076/jcen.26.1.74.23927.

Rogers, S. J., \& Ozonoff, S. (2005). Annotation: What do we know about sensory dysfunction in autism? A critical review of the empirical evidence. Journal of Child Psychology and Psychiatry and Allied Disciplines, 46, 1255-1268. doi:10.1111/j.1469-7610. 2005.01431.x.

Russell, J. (1997). Autism as an executive disorder. Oxford: Oxford University Press.

Sanders, A. F. (1998). Elements of human performance: Reaction processes and attention in human skill. New Jersey: Lawrence Erlbaum Associates.

Schmitz, N., Rubia, K., Daly, E., Smith, A., Williams, S., \& Murphy, D. G. M. (2006). Neural correlates of executive function in autistic spectrum disorders. Biological Psychiatry, 59, 7-16. doi: 10.1016/j.biopsych.2005.06.007.

Schoen, S. A., Miller, L. J., Brett-Green, B., Reynolds, S., \& Lane, S. J. (2008). Arousal and reactivity in children with sensory processing disorder and autism specturm disorder. Psychophysiology, 45, S102.

Sergeant, J. A., Geurts, H. M., \& Oosterlaan, J. (2002). How specific is a deficit of executive functioning for attention-deficit/ hyperactivity disorder? Behavioural Brain Research, 130, 3-28. doi:10.1016/S0166-4328(01)00430-2.

Solomon, M., Ozonoff, S. J., Cummings, N., \& Carter, C. S. (2008). Cognitive control in autism spectrum disorders. International Journal of Developmental Neuroscience, 26, 239-247. doi: 10.1016/j.ijdevneu.2007.11.001. 